\title{
Rancang Bangun Aplikasi Perepresentasian Data Perilaku Pengemudi Mobil Berbasis Android Menggunakan Sensor Accelerometer dan Orientation
}

\author{
Muhammad Dery Rahma, Daniel O. Siahaan, dan Rully Soelaiman \\ Jurusan Teknik Informatika, Fakultas Teknologi Informasi, Institut Teknologi Sepuluh Nopember \\ (ITS) \\ Jl. Arief Rahman Hakim, Surabaya 60111 Indonesia \\ e-mail:danielos@cs.its.ac.id, rully@is.its.ac.id,m.dery.rahma@gmail.com
}

\begin{abstract}
Abstrak-Semakin meningkatnya popularitas smartphone dari tahun ke tahun, semakin meningkat pula jumlah aplikasi perangkat bergerak yang berkaitan dengan keamanan dalam berkemudi. Oleh karena itu, diperlukan aplikasi perangkat bergerak lain yang dapat mendeteksi pergerakan mobil yang normal dan berbahaya menggunakan sensor accelerometer dan orientation yang berasal dari smartphone serta tanpa memerlukan sensor hardware tambahan. Arsitektur aplikasi perangkat bergerak ini berbasis client-server, dimana web service melayani permintaan dari aplikasi client berbasis Android. Aplikasi ini juga menggabungkan beberapa teknologi lain seperti Geolocation API, Geocoding API, dan Android Sensor API. Teknologi-teknologi tersebut digunakan untuk mengetahui kecepatan mobil, lokasi terkini dari pengemudi, dan merekam pola gerakan mobil melalui representasi nilai-nilai sensor accelerometer dan orientation. Tujuan dari dikembangkannya aplikasi perangkat bergerak untuk tugas akhir ini adalah untuk membantu pihak kepolisian lalu lintas dalam mendapatkan data pergerakan mobil berupa raw data 2-axis yang direkam oleh sensor accelerometer dan orientation pada smartphone Android ketika pengemudi mengendarai mobil. Data-data tersebut nantinya digunakan untuk membantu mendeteksi riwayat pola berkendara seorang pengemudi.
\end{abstract}

Kata Kunci-accelerometer, android, geolocation, orientation

\section{PENDAHULUAN}

$\mathrm{K}$ ECELAKAAN lalu lintas merupakan sebuah masalah sosial dan sudah menjadi hal yang biasa bagi masyarakat Indonesia. Hal ini karena intensitas kejadiannya yang makin tinggi. Menurut data statistik dari World Health Organization (WHO), kecelakaan lalu lintas menjadi salah satu dari 10 kasus penyebab kematian tertinggi di dunia [1]. Secara khusus, kecelakaan lalu lintas terjadi kurang lebih sebanyak 3500 kejadian setiap hari pada tahun 2014. Data dari kementerian perhubungan yang terdapat pada Gambar 1 menggambarkan kecelakaan lalu lintas yang terjadi pada tahun 2008-2012 [2].

Grafik pada Gambar 2 menunjukkan dari tahun 2008 - 2012 jumlah kendaraan bermotor makin meningkat. Dengan meningkatnya jumlah kendaraan bermotor tiap tahunnya, maka volume jalan raya pun kian padat. Dapat disimpulkan bahwa dengan berbanding lurusnya jumlah kendaraan dan jumlah kecelakaan dengan waktu, maka terdapat hubungan antara jumlah kendaraan dengan jumlah kecelakaan. Studi menunjukkan bahwa mayoritas penyebab kecelakaan lalu lintas adalah faktor human error, contohnya mengendarai mobil dengan pergerakan yang berbahaya dan tidak normal [4].

Maka dari itu, diperlukan aplikasi perangkat bergerak untuk mendeteksi apakah pergerakan mobil dikatakan normal atau berbahaya. Menurut [3], ada 6 jenis pergerakan berbahaya dalam mengemudikan mobil. Jenis-jenisnya antara lain Weaving, Swerving, Sideslipping, Fast U-turn, Turning with a wide radius, dan Sudden braking. Walaupun sudah ada percobaan [5] [6] [7] untuk mendeteksi pergerakan berbahaya dalam mengemudikan mobil, fokus percobaan itu masih menggunakan sensor yang ditanam pada suatu hardware dan terpisah dari smartphone. Contohnya sensor alkohol, sensor inframerah, dan sensor kamera. Semua sensor tersebut menghabiskan biaya pemasangan yang tinggi.

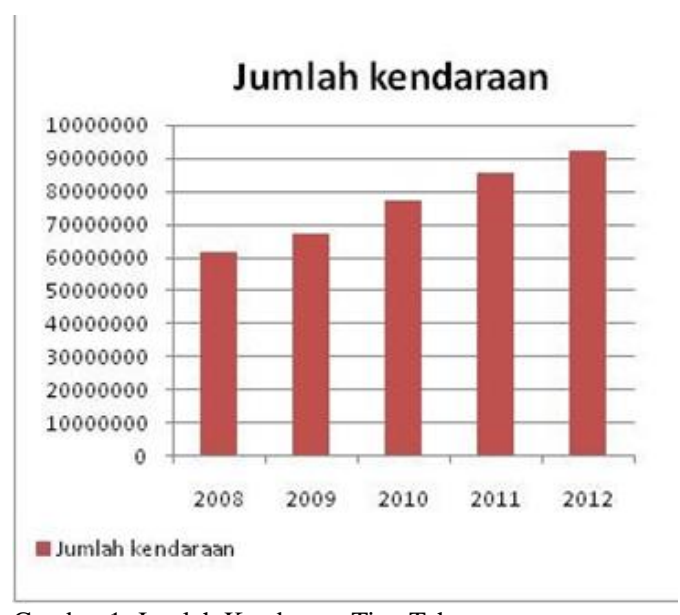

Gambar 1. Jumlah Kendaraan Tiap Tahun

Semakin meningkatnya popularitas smartphone dari tahun ke tahun [9], semakin meningkat pula jumlah aplikasi perangkat bergerak yang berkaitan dengan keamanan dalam berkemudi. Oleh karena itu, diperlukan aplikasi perangkat bergerak lain yang dapat mendeteksi pergerakan mobil yang normal dan berbahaya menggunakan sensor accelerometer dan orientation yang berasal dari smartphone serta tanpa memerlukan sensor 
hardware tambahan. Tujuan dari dikembangkannya aplikasi perangkat bergerak untuk tugas akhir ini adalah untuk membantu petugas kepolisian dalam mendapatkan data pergerakan mobil berupa raw data 2-axis yang direkam oleh sensor accelerometer dan orientation pada smartphone Android ketika pengemudi mengendarai mobil.

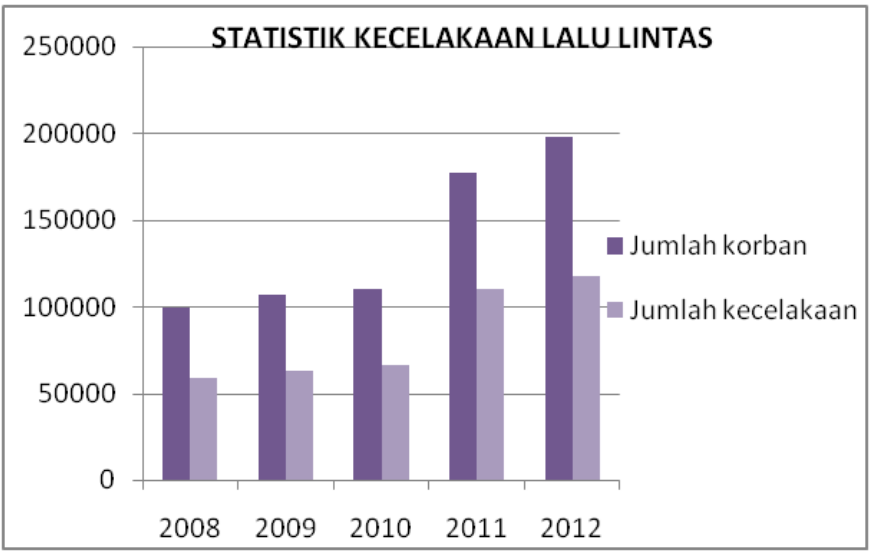

Gambar 2. Statistik Kecelakaan Lalu Lintas Tiap Tahun

\section{TINJAUAN PUSTAKA}

\section{A. REST Web Service}

REST adalah singkatan dari Representational State Transfer. Merupakan standar dalam arsitektur web yang menggunakan Protocol HTTP untuk pertukaran data. Pertama-tama, REST server menyediakan jalur untuk akses resource atau data, sedangkan REST client melakukan akses resource dan kemudian menampilkan atau menggunakannya. Resource yang dihasilkan sebenarnya berupa teks, namun formatnya bisa bermacam-macam tergantung keinginan developer, umumnya adalah JSON dan XML [13].

B. Volley

Volley adalah library yang dikembangkan oleh Google yang berfungsi untuk mengatur network request pada aplikasi perangkat bergerak [12].

\section{Geolocation API}

Teknologi yang dikembangkan oleh Google yang berfungsi untuk mendeteksi lokasi terkini dari suatu device Android. Selain itu, teknologi ini juga dapat dimanfaatkan untuk mendapatkan kecepatan dari kendaraan yang di dalamnya terdapat device Android dengan memanfaatkan sinyal GPS [8].

\section{Geocoding API}

Teknologi yang dikembangkan oleh Google yang berfungsi untuk mendapatkan alamat lengkap suatu lokasi dengan memanfaatkan nilai longitude dan latitude yang ditangkap oleh sinyal GPS [8].

\section{E. Sensor Accelerometer}

Salah satu tipe motion sensor pada Android yang berguna untuk mengukur percepatan yang diterapkan pada perangkat Android, termasuk gaya gravitasi [10].

\section{F. Sensor Orientation}

Salah satu tipe position sensor pada Android yang berguna untuk memantau posisi atau orientasi perangkat Android relatif terhadap permukaan bumi [11].

\section{G. Gerakan Weaving}

Mengemudi dari sisi satu ke sisi sebelahnya secara bergantian. Berawal dari satu sisi jalan, lalu ke sisi jalan yang lain, lalu kembali ke sisi jalan sebelumnya, dan seterusnya [14].

\section{H. Gerakan Swerving}

Melakukan manuver ke sisi jalan yang berlawanan secara tiba-tiba ketika mengemudi di jalan yang relatif lurus [14].

\section{Gerakan Fast U-turn}

Gerakan putar balik $\left(180^{\circ}\right)$ secara cepat dan kemudian mengemudi di arah yang berlawanan [14].

\section{J. Gerakan Turning with Wide Radius}

Berbelok melewati persimpangan atau tingkungan dengan kecepatan tinggi sehingga gerakannya seakan membentuk kurva dengan radius yang besar. Hal ini terkadang menyebabkan mobil keluar jalur [14].

\section{K. Gerakan Sudden Braking}

Pengereman mendadak yang menyebabkan kecepatan mobil berkurang drastis dalam kurun waktu yang singkat [14].

\section{Seleksi Fitur}

Pada paper [14] yang menjadi rujukan, penulis menemukan 16 fitur efektif yang mampu menangkap pola berbeda dari tiap tipe gerakan dalam berkendara. Daftar fiturnya dapat dilihat pada Gambar 3.

\begin{tabular}{|c|c|}
\hline Feature & Description \\
\hline range $_{a c c, x}$ & subtraction of maximum minus minimum value of $a c c_{x}$ \\
\hline range $_{a c c, y}$ & subtraction of maximum minus minimum value of $a c c_{y}$ \\
\hline$\sigma_{a c c, x}$ & standard deviation of $a c c_{x}$ \\
\hline$\sigma_{a c c, y}$ & standard deviation of $a c c_{y}$ \\
\hline$\sigma_{\text {ori,x }}$ & standard deviation of $o r i_{x}$ \\
\hline$\sigma_{\text {ori,y }}$ & standard deviation of $o r i_{y}$ \\
\hline$\mu_{a c c, x}$ & mean value of $a c c_{x}$ \\
\hline$\mu_{a c c, y}$ & mean value of $a c c_{y}$ \\
\hline$\mu_{\text {ori,x }}$ & mean value of ori $_{x}$ \\
\hline$\mu_{\text {ori,y }}$ & mean value of ori $_{y}$ \\
\hline$\mu_{a c c, x, 1}$ & mean value of $1^{s t}$ half of $a c c_{x}$ \\
\hline$\mu_{a c c, x, 2}$ & mean value of $2^{\text {nd }}$ half of $a c c_{x}$ \\
\hline $\max _{\text {ori }, x}$ & maximum value of ori $_{x}$ \\
\hline $\max _{\text {ori,y }}$ & maximum value of $o r i_{y}$ \\
\hline $\min _{a c c, y}$ & minimum value of $a c c_{y}$ \\
\hline$t$ & $\begin{array}{l}\text { time duration between the begining and the ending of a } \\
\text { driving behavior }\end{array}$ \\
\hline
\end{tabular}

Gambar 3. Fitur Hasil Ekstraksi

\section{Hukum III Newton}

Gaya aksi dan reaksi dari dua benda memiliki besar yang sama, dengan arah terbalik, dan segaris. Artinya, jika ada benda A yang memberi gaya sebesar F pada benda B, maka benda B 
akan memberi gaya sebesar $-\mathrm{F}$ kepada benda $\mathrm{A}$. $\mathrm{F}$ dan $-\mathrm{F}$ memiliki besar yang sama namun arahnya berbeda. Hukum ini juga terkenal sebagai hukum aksi-reaksi, dengan $\mathrm{F}$ disebut sebagai aksi dan $-\mathrm{F}$ adalah reaksinya [11].

\section{N. Low-Pass Filter}

Filter yang hanya melewatkan sinyal dengan frekuensi yang lebih rendah dari frekuensi cut-off (fc) dan akan melemahkan sinyal dengan frekuensi yang lebih tinggi dari frekuensi cut-off (fc) [9].

\section{ANALISIS DAN PERANCANGAN SISTEM}

\section{A. Analisis Permasalahan}

Human error adalah salah satu dari tiga faktor yang berkontribusi dalam kecelakaan lalu lintas, dua yang lainnya adalah kondisi kendaraan dan infrastruktur jalan. Faktor-faktor yang mengarah ke perilaku mengemudi mobil yang agresif adalah dari manuver mengemudi yang berbeda-beda atau kejadian yang muncul selama perjalanan, seperti gerakan Weaving, Swerving, Sideslipping, Fast U-turn, Turning with a wide radius, dan Sudden braking. Oleh karena itu, sangatlah penting untuk dapat mendeteksi gerakan mobil yang normal dan beberapa gerakan mobil yang berbahaya seperti yang telah disebutkan sebelumnya. Semua sistem pemantauan perilaku pengemudi yang ada sejauh ini memanfaatkan perekam data yang tertanam di dalam mobil yang mempunyai kemampuan untuk menyimpan data mengemudi yang relevan agar berguna untuk mendeteksi jenis gerakan yang dilakukan pengemudi. Namun, perekam-perekam data tersebut tidak fleksibel karena hanya dapat tertanam pada satu mobil saja dan tidak dapat dilepas serta dipindahkan agar dapat digunakan di mobil yang lain. Penulis mengembangkan alternatif untuk menggantikan perekam data yang tertanam di mobil dengan smartphone karena mudah diakses, tersedia secara luas, dan menghabiskan biaya yang relatif lebih rendah dibandingkan dengan perekam data yang tertanam di mobil. Selain itu, model smartphone saat ini sudah dilengkapi dengan fitur multisensor yang mempunyai kemampuan mirip dengan perekam data yang tertanam di mobil-mobil kelas atas. Berdasarkan pilihan-pilihan yang ada, sangat jelas bahwa smartphone menjadi kandidat yang bagus untuk digunakan sebagai alat yang mampu mengumpulkan, memproses, dan menganalisis data perilaku mengemudi. Selain itu, data-data tersebut dapat dimanfaatkan untuk mengklasifikasikan dan mendeteksi perilaku mengemudi yang normal atau berbahaya sehingga perilaku pengemudi dapat dikontrol.

Salah satu sensor yang dapat digunakan pada smartphone adalah accelerometer. Data-data pada accelerometer dapat dimanfaatkan untuk mengenali pergerakan membujur dan lateral dari suatu kendaraan. Pada saat yang bersamaan, GPS receiver pada smartphone dapat memberikan informasi mengenai data lokasi terkini dari kendaraan.

\section{B. Deskripsi Umum Sistem}

Dalam sistem yang dikembangkan pada paper [14] yang dapat dilihat pada Gambar 4, pengemudi yang mengemudikan mobilnya secara tidak normal dapat dideteksi dan diidentifikasi berdasarkan data yang direkam sensor accelerometer dan orientation pada smartphone pengemudi. Secara keseluruhan, sistem yang dipaparkan pada paper terbagi menjadi dua bagian, yaitu pemodelan perilaku mengemudikan mobil secara offline dan pemantauan perilaku mengemudikan mobil secara online.

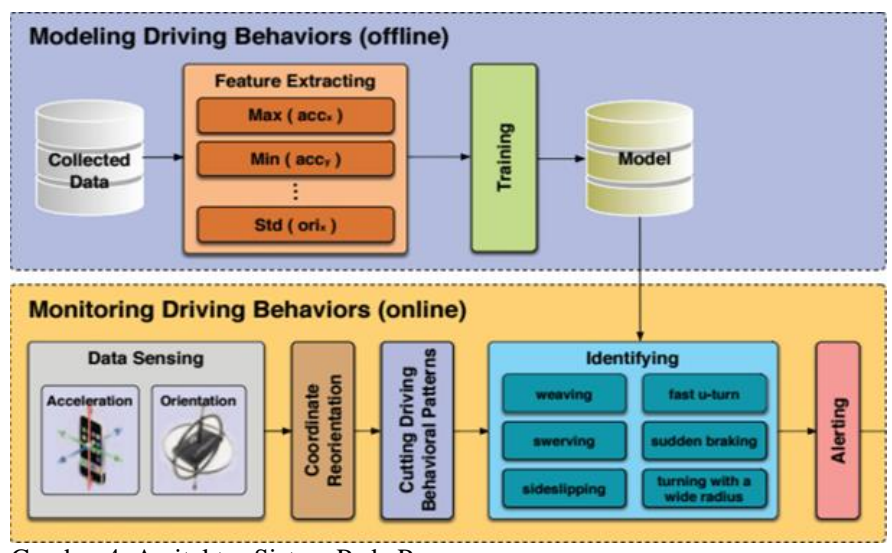

Gambar 4. Arsitektur Sistem Pada Paper

Pada bagian offline, aplikasi melakukan training pada model klasifikasi menggunakan teknik machine learning berdasarkan data yang telah dikumpulkan, yang mana nantinya dapat mengidentifikasi tipe spesifik dari perilaku mengemudikan mobil. Pada bagian Feature Extracting, fitur-fitur yang efektif diekstraksi dari pola-pola perilaku mengemudikan mobil pada bagian akselerasi dan orientasi. Pada bagian Training, fitur-fitur tadi di-training dan model klasifikasi pun dapat terbentuk. Akhirnya, model klasifikasi menghasilkan output dan disimpan di database Model.

Pada bagian online, fitur pemantauan perilaku mengemudikan mobil terinstal pada smartphone. Pertamatama, aplikasi membaca nilai akselerasi dan orientasi pada mobil dengan memanfaatkan sensor accelerometer dan orientation pada smartphone. Setelah mendapatkan perekaman data secara real-time oleh sensor accelerometer dan orientation, Coordinate Reorientation dilakukan untuk menyelaraskan sistem koordinat pada smartphone dengan mobil. Pada bagian Cutting Driving Behavioral Patterns, awal dan akhir dari perilaku mengemudikan mobil dapat diselidiki dari perekaman sensor accelerometer and orientation. Pada bagian Identifying, aplikasi melakukan ekstraksi fitur dari polapola perilaku mengemudikan mobil, lalu menentukan apakah salah satu dari perilaku tidak normal dalam mengemudikan mobil muncul berdasarkan model klasifikasi yang sudah ditraining. Terakhir, jika ada perilaku tidak normal dalam mengemudikan mobil yang teridentifikasi, pesan peringatan berupa Alert akan ditampilkan.

Pada Tugas Akhir ini, penulis hanya akan mengimplementasikan perancangan perangkat lunak sampai pada tahap pencatatan dan perepresentasian data-data 2-axis yang direkam oleh sensor accelerometer dan orientation pada smartphone Android ketika pengemudi mengendarai mobil secara real-time. Proses kalkulasi enam belas fitur dilakukan oleh aplikasi yang sudah terinstall di smartphone pengemudi. Proses analisis data dan penghitungan tingkat akurasi data ketika diklasifikasikan dilakukan secara offline. 


\section{Kasus Penggunaan}

Kasus penggunaan pada sistem dapat dilihat pada Tabel 1.

Tabel 1.

Kasus Penggunaan Sistem

\begin{tabular}{clc}
\hline $\begin{array}{c}\text { Kode Kasus } \\
\text { Penggunaan }\end{array}$ & \multicolumn{1}{c}{ Nama } & Aktor \\
\hline UC-0001 & $\begin{array}{l}\text { Mengaktifkan sensor pada } \\
\text { smartphone } \\
\text { Uenonaktifkan sensor pada } \\
\text { smartphone }\end{array}$ & Pengemudi \\
UC-0003 & $\begin{array}{l}\text { Melihat kecepatan kendaraan } \\
\text { menurut GPS }\end{array}$ & Pengemudi \\
UC-0004 & $\begin{array}{l}\text { Melihat lokasi terkini pengemudi } \\
\text { UC-0005 }\end{array}$ & $\begin{array}{l}\text { Pelihat detail profil pengemudi } \\
\text { Pengemudi }\end{array}$ \\
UC-0006 & $\begin{array}{l}\text { Melihat detail profil petugas } \\
\text { Mengunduh riwayat data sensor } \\
\text { UC-0007 pengemudi }\end{array}$ & Petugas \\
UC-0008 & $\begin{array}{l}\text { Menghapus riwayat data sensor } \\
\text { pengemudi }\end{array}$ & Petugas \\
\hline \hline
\end{tabular}

\section{Perancangan Arsitektur Sistem}

Smartphone pada arsitektur sistem berfungsi sebagai perangkat yang digunakan pengguna untuk mengakses aplikasi. Pengguna melakukan proses bisnis melalui halaman antarmuka yang disediakan sistem. Data-data aktivitas pergerakan mobil yang terekam disimpan di berkas berformat csv yang terdapat pada bagian Internal Storage. Aplikasi akan mengirim 2 jenis request, antara lain string request dan JSON object request. Sistem mengirim string request ke web service pada kasus penggunaan UC-0003 dan UC-0008. Sistem pada web service akan menerima data dari aplikasi dan menyimpannya ke dalam database yang sudah dibuat. Jika data berhasil disimpan, query response memberikan nilai true dan web service akan mengirimkan JSON post response ke aplikasi. Di sisi lain, sistem mengirim JSON object request ke web service pada kasus penggunaan UC-0004, UC-0005, UC-0006, dan UC0007. Sistem pada web service akan melakukan request pengambilan data ke database. Jika data berhasil diambil, web service akan mengirim JSON get response ke aplikasi. Visualisasi dari perancangan arsitektur sistem dapat dilihat pada Gambar 5.

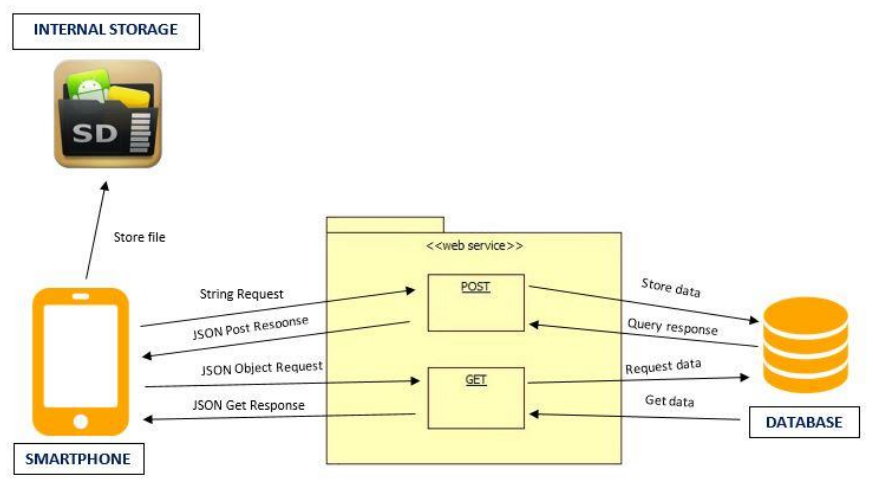

Gambar 5. Arsitektur Sistem

\section{IMPLEMENTASI}

\section{A. Implementasi Antarmuka}

Contoh implementasi antarmuka aplikasi dapat dilihat pada Gambar 6 dan Gambar 7.

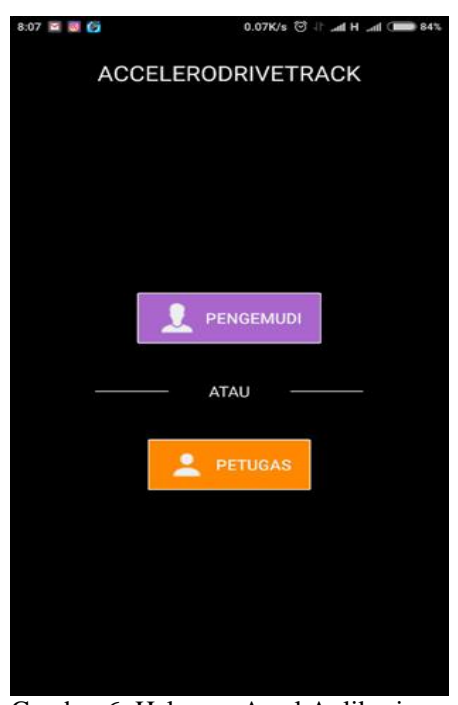

Gambar 6. Halaman Awal Aplikasi

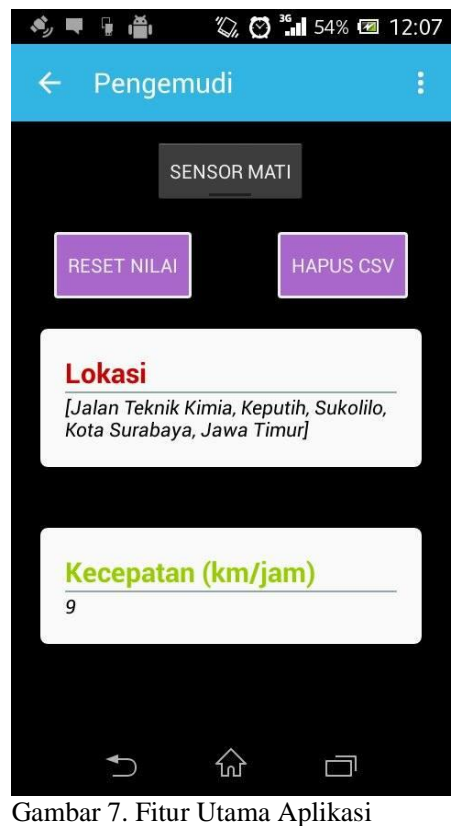

\section{PENGUJIAN DAN EVALUASI}

\section{A. Analisis Data}

- Analisis Data pada Gerakan Normal

Mengemudi dengan gerakan normal berarti mengemudi secara aman dengan fluktuasi yang sedikit dan kecil. Hal ini terlihat dari nilai minimum, maksimum, rata-rata, dan standar deviasi akselerasi pada sumbu $\mathrm{x}$ dan y yang mendekati angka 0 seperti yang terlihat pada Gambar 8. Selain itu, nilai standar deviasi dan nilai rata-rata orientasi pada sumbu $\mathrm{x}$ dan $\mathrm{y}$ juga relatif kecil. Nilai $t$ (durasi) pada gerakan normal bervariasi 
tergantung kapan pengemudi menyelesaikan satu gerakan normal. Grafiknya dapat dilihat pada Gambar 8.

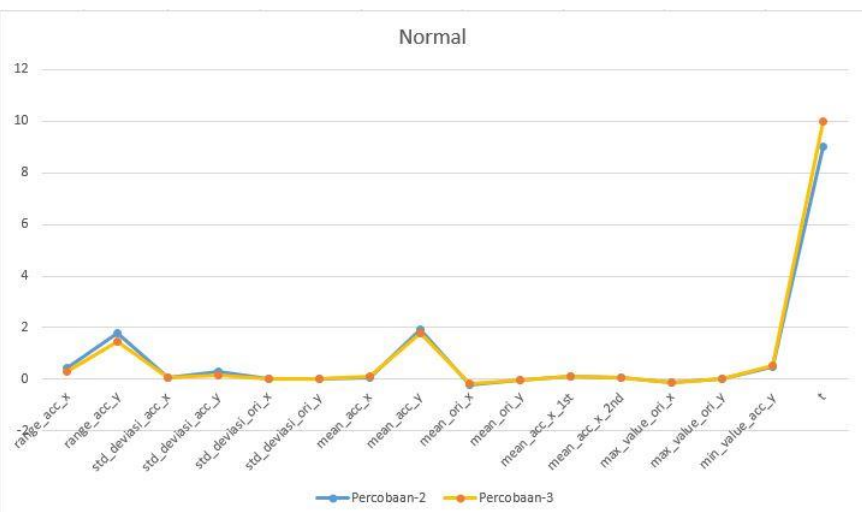

Gambar 8. Grafik Data Gerakan Normal

- Analisis Data pada Gerakan Weaving

Mengemudi dengan gerakan weaving berarti mengemudi secara zigzag (berliku-liku) dari kiri ke kanan dan sebaliknya. Hal ini terlihat dari nilai standar deviasi $a c c_{x}$ dan rentang nilai $a c c_{x}$ yang relatif besar seperti yang terlihat pada Gambar 9. Selain itu, nilai rata-rata $a c c_{x}$ masih pada kisaran angka 0 . Nilai $t$ (durasi) tinggi karena butuh waktu yang relatif panjang untuk menyelesaikan satu gerakan weaving sampai selesai.

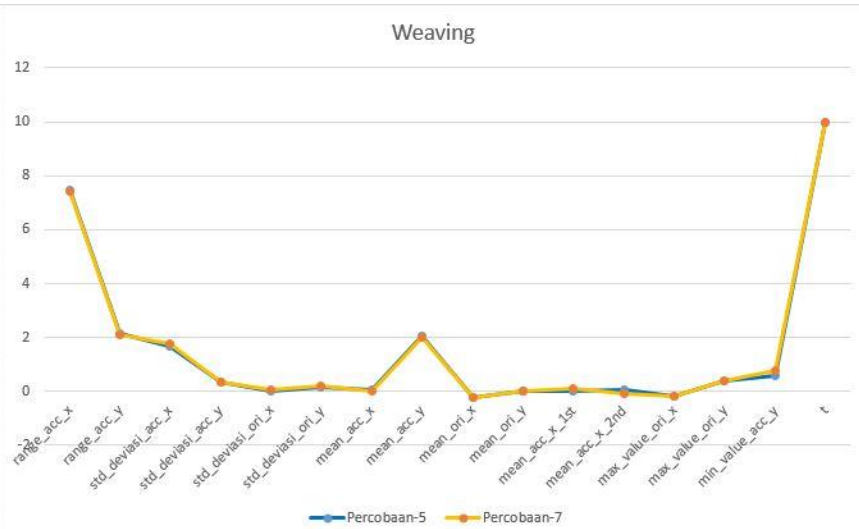

Gambar 9. Grafik Data Gerakan Weaving

- Analisis Data pada Gerakan Swerving

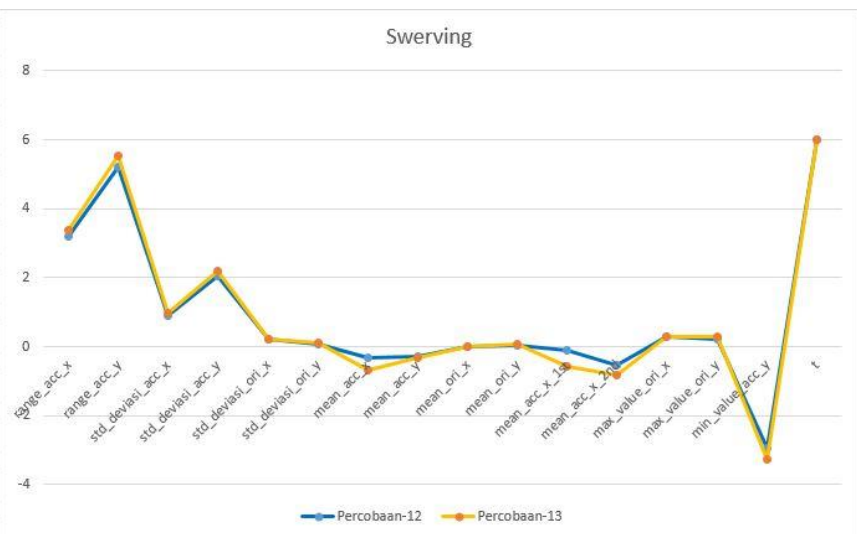

Gambar 10. Grafik Data Gerakan Swerving
Mengemudi dengan gerakan swerving berarti melakukan manuver ke sisi jalan yang berlawanan secara tiba-tiba. Hal ini terlihat dari rentang nilai $a c c_{x}$ dan $o r i_{x}$ yang relatif besar. Selain itu, nilai standar deviasi $a c c_{x}$ dan $\operatorname{ori}_{x}$ juga lebih dari 0. Nilai rata-rata $a c c_{x}$ dan ori $_{x}$ relatif tidak mendekati 0 karena manuver pada gerakan swerving mengubah arah kemudi. Otomatis, nilai rata-rata $a c c_{x}$ paruh pertama dan paruh kedua juga tidak mendekati 0. Grafik dapat dilihat pada Gambar 10.

- Analisis Data pada Gerakan Fast U-turn

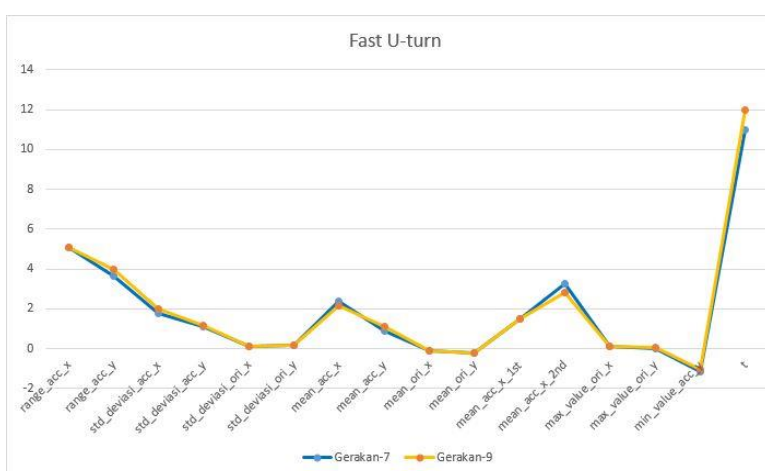

Gambar 11. Grafik Data Gerakan Fast U-turn

Mengemudi dengan gerakan fast u-turn berarti melakukan perputaran 180 derajat pada jalur putar balik dengan kecepatan relatif tinggi. Hal ini terlihat dari rentang nilai $a c c_{x}$ dan nilai rata-rata $a c c_{x}$ yang jauh dari 0 . Nilai $t$ (durasi) besar karena butuh waktu yang relatif besar untuk menyelesaikan satu gerakan fast u-turn. Grafiknya dapat dilihat pada Gambar 11.

- Analisis Data pada Gerakan Turning with Wide Radius

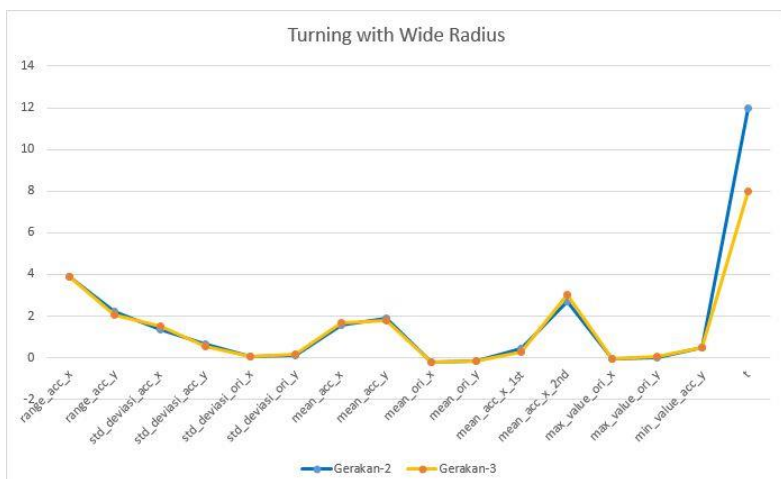

Gambar 12. Grafik Data Gerakan Turning with Wide Radius

Mengemudi dengan gerakan turning with wide radius berarti melewati tikungan yang mempunyai radius besar dengan kecepatan relatif tinggi. Hal ini terlihat dari nilai rata-rata $a c c_{x}$ dan standar deviasi $a c c_{x}$ yang jauh dari 0 karena kedua percobaan dilakukan dengan melalui tikungan yang cenderung ke arah kanan. Nilai rata-rata $a c c_{y}$ tinggi karena gerakan dilakukan dengan kecepatan tinggi. Nilai $t$ (durasi) besar karena butuh waktu yang relatif besar untuk menyelesaikan satu gerakan turning with wide radius. Grafiknya dapat dilihat pada Gambar 12.

- Analisis Data pada Gerakan Sudden Braking 
Mengemudi dengan gerakan sudden braking adalah ketika pengemudi melakukan pengereman mendadak pada saat berkendara dengan kecepatan relatif tinggi. Hal ini terlihat dari rentang nilai $a c c_{y}$, nilai rata-rata $a c c_{y}$, dan standar deviasi $a c c_{y}$ yang relatif tinggi. Di sisi lain, rentang nilai $a c c_{\mathrm{x}}$. Selain itu, nilai minimum dari $a c c_{y}$ jauh di bawah 0 karena adanya pengereman mendadak. Grafiknya dapat dilihat pada Gambar 13.

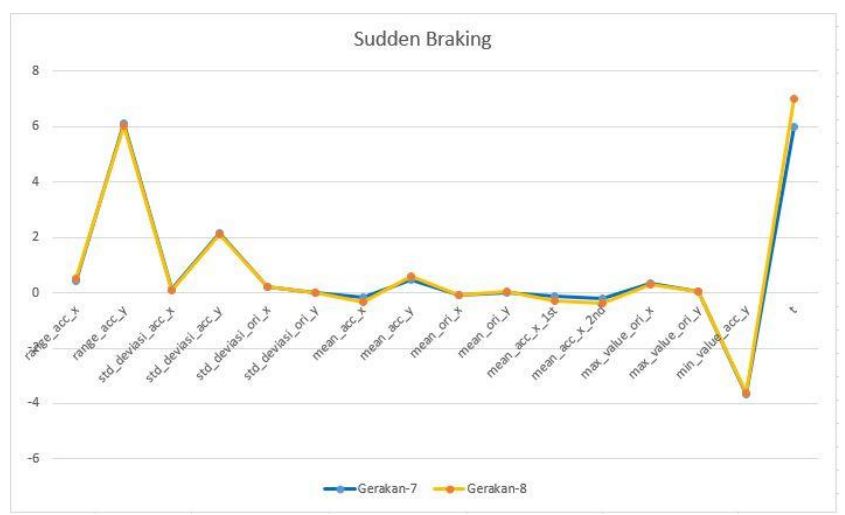

Gambar 13. Grafik Data Gerakan Sudden Braking

\section{B. Pengujian Akurasi}

Hasil pengujian akurasi dengan menggunakan kakas bantu Weka v3.8 dapat dilihat pada Tabel 2.

Tabel 2.

Hasil Pengujian Tingkat Akurasi Data

\begin{tabular}{clc}
\hline \hline Kode Pengujian & \multicolumn{1}{c}{ Jenis Pengujian } & Hasil \\
\hline SCA-001 & $\begin{array}{l}\text { Fitur Acuan } \\
\text { Fitur Acuan dan Fitur }\end{array}$ & $88.8889 \%$ \\
SCA-002 & $\begin{array}{l}\text { Rata-Rata } a c c_{x} \\
\text { Fitur Acuan dan Fitur }\end{array}$ & $92.2963 \%$ \\
SCA-003 & $\begin{array}{l}\text { Rata-Rata } a c c_{y} \\
\text { Fitur Acuan dan Rata- }\end{array}$ & $92.5926 \%$ \\
SCA-004 & $\begin{array}{l}\text { Rata } \text { ori }_{x} \\
\text { Fitur Acuan dan Fitur }\end{array}$ & $96.2963 \%$ \\
SCA-005 & $\begin{array}{l}\text { Rata-Rata } \text { ori }_{y} \\
\text { Fitur Acuan dan Fitur } \\
\text { Rata-Rata } a c c_{x} 1^{s t}\end{array}$ & $92.5926 \%$ \\
SCA-006 007 & $\begin{array}{l}\text { Fitur Acuan dan Fitur } \\
\text { Rata-Rata } a c c_{x} 2^{\text {nd }}\end{array}$ & $96.2963 \%$ \\
SCA-008 & $\begin{array}{l}\text { Fitur Acuan dan Nilai } \\
\text { Maksimum } \text { ori }_{x}\end{array}$ & $88.8889 \%$ \\
SCA-009 & $\begin{array}{l}\text { Fitur Acuan dan Nilai } \\
\text { Maksimum } \text { ori }_{y}\end{array}$ & $92.5926 \%$ \\
SCA-010 & $\begin{array}{l}\text { Fitur Acuan dan Nilai } \\
\text { Minimum } a c c_{y}\end{array}$ & $92.5926 \%$ \\
SCA-011 & Fitur Acuan dan Nilai $t$ & $92.5926 \%$ \\
\hline \hline
\end{tabular}

\section{KESIMPULAN/RINGKASAN}

Aplikasi perangkat bergerak yang dibangun pada paper ini dapat menampilkan kecepatan dan lokasi terkini kendaraan menurut sinyal GPS yang ditangkap oleh smartphone. Selain itu, aplikasi juga dapat mengumpulkan data-data sensor accelerometer dan orientation yang nantinya digunakan untuk mengenali pola masing-masing gerakan yang sudah disebutkan pada Bab II. Tingkat akurasi data-data yang dikumpulkan mencapai $92.5926 \%$.

\section{UCAPAN TERIMA KASIH}

Penulis M.D.R. mengucapkan terima kasih kepada Allah SWT, kedua orang tua, saudara, dan dosen pembimbing, yang telah membimbing penulis selama berkuliah di Teknik Informatika ITS.

\section{DAFTAR PUSTAKA}

[1] "Perhubungan Darat Dalam Angka Edisi 2012," 17 Desember 2015. [Online]. Available: http://hubdat.dephub.go.id/data-ainformasi/pdda/tahun-2012.

[2] "The top ten causes of death," World.Health.Organisation., [Online]. Available: http://www.who.int/mediacentre/factsheets/fs310/en/. [Accessed 17 Desember 2015].

[3] "The visual detection of dwi motorists," 22 Desember 2015. [Online]. Available: http://www.shippd.org/Alcohol/dwibooklet.pdf.

[4] F. K. Y. Z. a. F. M. J. Paefgen, "Driving behavior analysis with smartphones: insights from a controlled field study," IEEE, 2009.

[5] X. L. K. S. a. E. P. W.-S. M. V. Yeo, "Can svm be used for automatic eeg detection of drowsiness during car driving?," in Elsevier Safety Science, Los Angeles, Amazon Publisher, 2009, pp. 115-124.

[6] C. S. a. W. Pattara-Atikom, "Smartphone enabled dangerous driving report system," Proc. HICSS, 2013.

[7] A. H.-B. a. H. Z. S. Al-Sultan, "Context-aware driver behavior detection system in intelligent transportaion system," IEEE Trans. on Vehicular Technology, p. 4264-4275, 2013

[8] Wikipedia, "Main Page," 2016. [Online]. Available: https://id.wikipedia.org/wiki/Android_(sistem_operasi).

[9] Techinasia, "Android mendominasi smartphone di Indonesia," 22 Desember 2015. [Online]. Available: https://id.techinasia.com/androidopera-dominasi-smartphone-indonesia-2014/.

[10] Android, "Motion Sensor," 29 July 2016. [Online]. Available: https://developer.android.com/guide/topics/sensors/sensors_motion.html

[11] Android, "Position Sensor," 29 July 2016. [Online]. Available: https://developer.android.com/guide/topics/sensors/sensors_position.htm 1 .

[12] Android, "Volley JSON," 29 July 2016. [Online]. Available: https://developer.android.com/training/volley/index.html.

[13] Wikipedia, "REST," 13 May 2016. [Online]. Available: https://en.wikipedia.org/wiki/Representational_state_transfer.

[14] J. Y. Y. Z. Y. C. a. M. L. Zhongyang Chen, "D3 : Abnormal Driving Behaviors Detection and Identification Using Smartphone Sensors," IEEE, pp. 1-20, 2015. 